\title{
Erratum to: Stock Indices in Emerging and Consolidated Economies from a Fractal Perspective
}

\author{
María Antonia Navascués, Maria Victoria Sebastián, and Mario Latorre
}

(C) Springer International Publishing Switzerland 2016

I. Rojas, H. Pomares (eds.), Time Series Analysis and Forecasting, Contributions to Statistics, DOI 10.1007/978-3-319-28725-6_9

In Chapter 9 titled "Stock Indices in Emerging and Consolidated Economies from a Fractal Perspective", the name of the author was incorrect. The name should read Mario Latorre instead of Miguel Latorre.

The updated original online version for this chapter can be found at DOI http://dx.doi.org/10.1007/978-3-319-28725-6_9

M.A. Navascués $(\varangle) \bullet$ M. Latorre

Escuela de Ingenieria y Arquitectura, Universidad de Zaragoza, C/ María de Luna 3, 50018

Zaragoza, Spain

e-mail:manavas@unizar.es; mario.latorrepellegero@gmail.com

http://pcmap.unizar.es/ navascues/

M.V. Sebastián

Centro Universitario de la Defensa. Academia General Militar de Zaragoza. Ctra. de Huesca s/n 50090 Zaragoza, Spain

e-mail: msebasti@unizar.es 